Medicine and Infectious Disease

Elsevier Editorial system(tm) for Travel

Manuscript Draft

Manuscript Number:

Title: Geographical accessibility to yellow fever travel vaccination centres in England, Wales, and Northern Ireland

Article Type: Original Article

Keywords: GEOGRAPHICAL ACCESSIBILITY, PREVENTIVE MEDICINE, VACCINATIONS, YELLOW FEVER

Corresponding Author: Dr. JAKOB PETERSEN,

Corresponding Author's Institution:

First Author: Jakob Petersen

Order of Authors: Jakob Petersen; Hilary Simons; Dipti Patel

Abstract: Background More than 700,000 trips were made by residents in England, Wales, and Northern Ireland (EWNI) to tropical countries endemic for yellow fever, a potentially deadly, yet vaccine-preventable disease transmitted by mosquitoes. The aim of the study was to map and ascertain the geographical accessibility of yellow fever vaccination centres (YFVC) in EWNI.

Methods The location of 3,208 YFVC were geocoded and the average geodetic distance to nearest YFVC was calculated for each population unit. Data on trips abroad and centres were obtained regionally for EWNI and nationally for the World Top20 countries in terms of travel.

Results The mean distance to nearest yellow fever vaccination centre was $2.4 \mathrm{~km}$ and only $1 \%$ of the population had to travel more than $16.1 \mathrm{~km}$ to their nearest centre. The number of vaccines administered regionally in EWNI was found correlated with the number of trips to yellow fever countries. The number of centres per 100,000 trips was 6.1 in EWNI, which was below United States (12.1) and above the rest of Top20 countries. Conclusions The geographical accessibility was good and the service availability in line with demand regionally. Variation in service accessibility internationally likely relates to different travel patterns/demand and differences in healthcare systems. 


\title{
Travel Medicine and Infectious Disease
}

\section{Conflict of Interest Policy}

Manuscript number (if applicable):

Article Title:

\author{
Author name:
}

\section{Declarations}

Travel Medicine and Infectious Disease requires that all authors sign a declaration of conflicting interests. If you have nothing to declare in any of these categories then this should be stated.

\section{Conflict of Interest}

A conflicting interest exists when professional judgement concerning a primary interest (such as patient's welfare or the validity of research) may be influenced by a secondary interest (such as financial gain or personal rivalry). It may arise for the authors when they have financial interest that may influence their interpretation of their results or those of others. Examples of potential conflicts of interest include employment, consultancies, stock ownership, honoraria, paid expert testimony, patent applications/registrations, and grants or other funding.

\section{Please state any competing interests}

\section{Funding Source}

All sources of funding should also be acknowledged and you should declare any involvement of study sponsors in the study design; collection, analysis and interpretation of data; the writing of the manuscript; the decision to submit the manuscript for publication. If the study sponsors had no such involvement, this should be stated.

Please state any sources of funding for your research

Signature (a scanned signature is acceptable, Print name but each author must sign) 


\section{Title}

1 Geographical accessibility to yellow fever travel vaccination centres in England, Wales, and Northern Ireland

Authors (* corresponding)

Jakob Petersen*, National Travel Health Network and Centre (NaTHNaC), University College London Hospital NHS Foundation Trust, London, UK, Telephone +44(0)2034475992, Jakob.petersen@uclh.nhs.uk.

Hilary Simons, National Travel Health Network and Centre (NaTHNaC), Liverpool School of Tropical Medicine, Liverpool, UK, Hilary.Simons@lstmed.ac.uk.

Dipti Patel, National Travel Health Network and Centre (NaTHNaC), University College London Hospital NHS Foundation Trust, London, UK, dipti.patel@uclh.nhs.uk.

\section{Abstract (200/200 words)}

Background More than 700,000 trips were made by residents in England, Wales, and Northern Ireland (EWNI) to tropical countries endemic for yellow fever, a potentially deadly, yet vaccine-preventable disease transmitted by mosquitoes. The aim of the study was to map and ascertain the geographical accessibility of yellow fever vaccination centres (YFVC) in EWNI.

Methods The location of 3,208 YFVC were geocoded and the average geodetic distance to nearest YFVC was calculated for each population unit. Data on trips abroad and centres were obtained regionally for EWNI and nationally for the World Top20 countries in terms of travel.

Results The mean distance to nearest yellow fever vaccination centre was $2.4 \mathrm{~km}$ and only $1 \%$ of the population had to travel more than $16.1 \mathrm{~km}$ to their nearest centre. The number of vaccines administered regionally in EWNI was found correlated with the number of trips to yellow fever countries. The number of centres per 100,000 trips was 6.1 in EWNI, which was below United States (12.1) and above the rest of Top20 countries.

Conclusions The geographical accessibility was good and the service availability in line with demand regionally. Variation in service accessibility internationally likely relates to different travel patterns/demand and differences in healthcare systems.

Key words $(\max 6)$

GEOGRAPHICAL ACCESSIBILITY, PREVENTIVE MEDICINE, VACCINATIONS, YELLOW FEVER 


\section{Introduction}

1

2 3 4 5 6 7 8

The populations of England, Wales, and Northern Ireland made more than 60 million trips abroad in 2015 [1].

More than 700,000 of these trips were made to countries endemic for yellow fever, a potentially deadly, tropical disease transmitted by mosquitoes. The disease is preventable by vaccination and this study was undertaken to elucidate the geographical accessibility of yellow fever vaccination centres.

Yellow fever control has been on the international public health agenda since 1851 and has remained a disease under tight international surveillance and control measures ever since together with diseases such as cholera, and pneumonic plague [2]. Due to its reservoir in monkey and other non-human primate populations in the rain forests of Africa and South America (the forest cycle is maintained with tree-living mosquitoes as vectors), yellow fever may never be eradicated [3]. The main control measure for yellow fever is therefore vaccination in combination with vector control in high risk areas as well as measures available to countries at risk of importing or exporting the disease such as vaccination certificate requirements, border vaccination, and emergency quarantine restrictions to reduce the international spread of the disease $[2,4,5]$.

Occasionally, there are large outbreaks in urban areas (urban cycle), where the transmission depends on the Aedes aegypti mosquito, which has spread in cities across the tropics in recent decades. A yellow fever outbreak in Angola and Democratic of Republic of Congo (DRC) in 2015-2016 with more than 7,000 suspected cases (965 confirmed cases and 137 confirmed deaths) was a stark reminder of the emerging threat of urban yellow fever outbreaks [6,7]. Increased international travel, urbanisation, and the fact that many tropical countries have large unvaccinated populations make the prospects of new urban yellow fever outbreaks a particular concern. At least 42 cases of international spread were recorded in connection with the Angola-DRC outbreak to countries with vector presence and largely unvaccinated populations including China and Kenya [8].

The National Travel Health Network and Centre (NaTHNaC) has overseen the registration, training, clinical standards, and audit of yellow fever vaccination centres in England, Wales, and Northern Ireland in compliance with the International Health Regulations for yellow fever since 2005 [9] and this is the first study to evaluate the geographical accessibility [10] of the yellow fever vaccination services. The aims of the study were thus to map and ascertain the geographical accessibility of yellow fever vaccination centres, match the number of trips to countries with yellow fever risk to the number of vaccinations given per region, identify any underserved 
populations and evaluate any need to regulate service provision, and gather data to support contingency

planning in the event of a vaccine shortage.

\section{Methods}

Administrative data on the postcode location of yellow fever vaccination centres were extracted from the Yellow Fever Vaccination Programme database (NaTHNaC, 27 October 2016). Occupational Health departments $(\mathrm{N}=218)$ were excluded as these by definition were not open to the general public. A total of 3,222 centres were registered. General practitioner (GP) practices were the most frequent type of centre $(\mathrm{N}=2,381)$. Of the 3,222 centres, 3,208 or 99.6\% could be geo-located to Census 2011 lower layer super output area (super output area for Northern Ireland; this is the nearest equivalent unit and it will be referred to as lower layer super output area hereinafter) and UK Region using the Office for National Statistics (ONS) Postcode Directory, August 2016 [11]. The latest mid-year population estimates (2015) were obtained at lower layer super output area level from ONS [12] and the Northern Ireland Statistics and Research Agency (NISRA) [13]. The analyses were conducted at lower layer super output area $(\mathrm{N}=35,643)$, which had a mean (SD) population of 1,676 (379). The average geodetic distance (crow-fly distance) from each population unit was calculated to each centre location using the Stata module, GEODIST [14] to determine the distance to the nearest centre at lower layer super output area level. The centres were assigned to distance categories according to the following population percentiles: $75^{\text {th }}, 90^{\text {th }}, 95^{\text {th }}$, and $99^{\text {th }}$. Data on the average number of vaccinations per centre across regions were obtained from annual surveys of the centres in 2013-2015 (NaTHNaC, unpublished data). Boundary data for Census output areas, UK Regions and countries were obtained from the UK Data Service/ Edinburgh University Data Library [15], which contains National Statistics data (ㄷ Crown copyright and database right, 2016), NRS data (C Crown copyright and database right, 2016, Source: NISRA Website, www.nisra.gov.uk; accessed 17 November 2016), and OS data (@ Crown copyright and database right, 2016). Boundary data for the Isle of Man, Republic of Ireland, and Scotland were obtained from Natural Earth (www.naturalearthdata.com; accessed 17 November 2016) . Maps were created using Quantum GIS 2.12 [16]. Data on trips abroad by UK region of residence undertaken in 2015 were obtained from ONS Social Surveys (Crown copyright; December 2016). Data on trips abroad by countries where the traveller spent most time and UK Region of residence were obtained from Office for National Statistics [1]. Data on countries with risk of yellow fever transmission were obtained from the World Health Organization [17]. Data on the number of 
registered yellow fever vaccination centres in other countries were obtained from ministries of health

1

2

3

4

5

6 7

8

9 10

websites, literature, and personal communication with health professionals (see references at Table 4). The numbers of trips abroad (departures) by country in $2013(\mathrm{~N}=100)$ were obtained from the World Bank data repository [18]. Data analyses were carried out in Stata 14 [19].

\section{Results}

The population weighted mean distance to nearest centre varied from $0.6 \mathrm{~km}$ in London to $7.1 \mathrm{~km}$ in Northern Ireland. The national mean distance was $2.4 \mathrm{~km}$ and the maximum distance $30.9 \mathrm{~km}$. Only $1 \%$ of the general population had more than $16.1 \mathrm{~km}$ to their nearest centre (99th percentile) (Table 1, Figure 1, Figure 2).

A total of 713,548 trips to countries with yellow fever transmission risk were made by residents in England, Wales, and Northern Ireland in 2015 (Table 2). Nigeria (20.7\%), Brazil (14.8\%), and Kenya (13.8\%) alone accounted for half of all trips and the ten most commonly visited countries combined accounted for $84.3 \%$ of all trips (Table 2).

The number of centres by UK Region varied from 51 in Northern Ireland to 858 in London. The number of centres per population varied from 2.8 per 100,000 population in Northern Ireland to 9.9 per 100,000 population in London. Nationally, there were 5.4 centres per 100,000 population (Table 3).

The size of the centres in terms of the yearly number of vaccines administered was calculated from data submitted in annual surveys in 2013-2015. The average number nationally was 40 vaccines per centre. The London average was the highest at 59 vaccines per centre followed by Northern Ireland (45), South East (40), North West (38), North East (38), East of England (34), South West (34), Yorkshire and The Humber (29), West Midlands (28), Wales (27) and East Midlands (25).

There was a linear relationship between the estimated number of yellow fever vaccines administered and the number of trips to countries with yellow fever risk by UK Region, which indicate that there is balance between supply and demand at the regional level (Figure 3).

The number of centres per 100,000 international trips abroad was 6.1 in England, Wales, and Northern Ireland, which was below that of United States (12.1) and above the rest of World Top20 countries in terms of trips abroad (Table 4). 
Table 1 Distance to nearest yellow fever vaccination centre for the general population by UK Region (km).

\begin{tabular}{|c|c|c|c|c|c|c|c|}
\hline 1 & Region & Min & Median & Mean & p75 & p99 & Max \\
\hline 2 & North East & 0.0 & 2.1 & 3.2 & 3.8 & 20.2 & 28.3 \\
\hline 3 & North West & 0.0 & 1.6 & 2.0 & 2.7 & 8.7 & 25.0 \\
\hline 4 & Yorkshire \& The Humber & 0.0 & 1.7 & 2.4 & 3.3 & 10.6 & 26.4 \\
\hline 6 & West Midlands & 0.0 & 1.5 & 2.1 & 2.5 & 11.5 & 17.3 \\
\hline 7 & East of England & 0.0 & 1.5 & 2.8 & 3.6 & 14.6 & 20.9 \\
\hline 8 & London & 0.0 & 0.5 & 0.6 & 0.8 & 2.2 & 4.0 \\
\hline 1 & Northern Ireland & 0.0 & 3.9 & 7.1 & 11.9 & 26.4 & 30.9 \\
\hline 2 & Wales & 0.0 & 3.2 & 4.9 & 7.5 & 22.0 & 29.3 \\
\hline L3 & Total & 0.0 & 1.3 & 2.4 & 2.9 & 16.1 & 30.9 \\
\hline
\end{tabular}

14 Note: The national $56^{\text {th }}$ percentile was $1.6 \mathrm{~km}$. The headers, $\mathrm{p} 75$ and p99, denote the $75^{\text {th }}$ and $99^{\text {th }}$ percentile, respectively.

16

17

18 Table 2 Top10 Trips abroad to countries with yellow fever risk made by residents in England, Wales, and Northern Ireland. Source:

19 International Passenger Survey 2015.

20

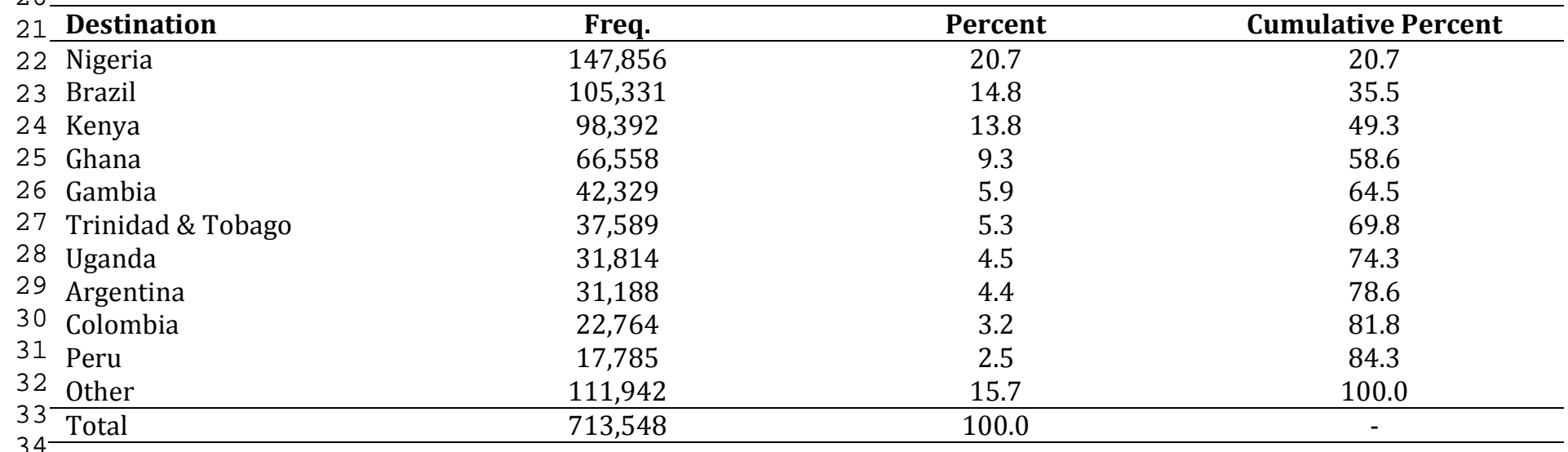

35

Table 3 Trips abroad by Region of residence in England, Wales, and Northern Ireland in 2015 compared to the number of yellow fever vaccination (YFV) centres. YF Trips: trips to countries with yellow fever risk. Trips data source: International Passenger Survey 2015.

\begin{tabular}{|c|c|c|c|c|c|c|c|}
\hline Region & $\begin{array}{c}\text { Trips } \\
\text { Abroad }\end{array}$ & YF Trips & $\begin{array}{c}\text { YFV } \\
\text { Centres }\end{array}$ & $\begin{array}{c}\text { Mean } \\
\text { Distance to } \\
\text { YFV Centre } \\
\text { (km) }\end{array}$ & $\begin{array}{c}\text { Centres } \\
\text { per } \\
100,000 \\
\text { Pop } \\
\end{array}$ & $\begin{array}{c}\text { Trips per } \\
100,000 \\
\text { Pop }\end{array}$ & $\begin{array}{c}\text { YF Trips } \\
\text { per } \\
100,000 \\
\text { Pop } \\
\end{array}$ \\
\hline London & $14,596,697$ & 350,422 & 858 & 0.6 & 9.9 & 168,287 & 4,040 \\
\hline South East & $10,338,088$ & 114,840 & 572 & 1.9 & 6.4 & 115,536 & 1,283 \\
\hline West Midlands & $4,806,320$ & 51,938 & 239 & 2.1 & 4.2 & 83,574 & 903 \\
\hline East of England & $5,777,899$ & 50,538 & 324 & 2.8 & 5.3 & 95,087 & 832 \\
\hline North West & $6,568,124$ & 39,169 & 251 & 2.0 & 3.5 & 91,557 & 546 \\
\hline South West & $4,629,680$ & 35,501 & 299 & 2.7 & 5.5 & 84,619 & 649 \\
\hline East Midlands & $3,774,532$ & 25,869 & 211 & 2.7 & 4.5 & 80,703 & 553 \\
\hline $\begin{array}{l}\text { Yorkshire \& The } \\
\text { Humber }\end{array}$ & $4,752,930$ & 23,817 & 208 & 2.4 & 3.9 & 88,171 & 442 \\
\hline North East & $1,844,388$ & 16,185 & 85 & 3.2 & 3.2 & 70,273 & 617 \\
\hline Wales & $2,183,671$ & 5,267 & 110 & 4.9 & 3.5 & 70,462 & 170 \\
\hline Northern Ireland & 803,150 & 0 & 51 & 7.1 & 2.8 & 43,376 & - \\
\hline Total & $60,075,479$ & 713,546 & 3,208 & 2.4 & 5.4 & 100,567 & 1,194 \\
\hline
\end{tabular}


Table 4 Yellow fever vaccination centres per international trips abroad by country.

\begin{tabular}{|c|c|c|c|c|}
\hline $\begin{array}{ll}1 & \text { Rank } \\
2 & \\
3 & \\
\end{array}$ & Country & $\begin{array}{l}\text { Trips abroad } \\
\text { (millions) }\end{array}$ & $\begin{array}{c}\text { Yellow fever } \\
\text { vaccination centres } \\
\text { (YFVC) }\end{array}$ & $\begin{array}{c}\text { YFVC per } 100,000 \\
\text { trips abroad }\end{array}$ \\
\hline $4 \overline{1}$ & China [20] & 98.2 & 168 & 0.2 \\
\hline 52 & Germany [21] & 87.5 & 2,072 & 2.4 \\
\hline 63 & Hong Kong SAR, China [22] & 84.4 & 2 & $<0.1$ \\
\hline 74 & United States [23] & 61.9 & 7,493 & 12.1 \\
\hline 85 & Russian Federation [24] & 54.1 & 44 & 0.1 \\
\hline 96 & England, Wales, N. Ireland & 53.0 & 3,208 & 6.1 \\
\hline 7 & Poland* & 52.6 & . & . \\
\hline 18 & Canada [25] & 33.0 & 1,050 & 3.2 \\
\hline 29 & Italy [26] & 27.8 & 330 & 1.2 \\
\hline 310 & France [27] & 26.2 & 162 & 0.6 \\
\hline $\begin{array}{ll}4 & 11\end{array}$ & Ukraine* & 23.8 & . & . \\
\hline 5 & Saudi Arabia [28] & 19.2 & 435 & 2.3 \\
\hline 613 & Netherlands [29] & 18.1 & 968 & 5.3 \\
\hline 14 & Japan [30] & 17.5 & 22 & 0.1 \\
\hline 15 & India [31] & 16.6 & 34 & 0.2 \\
\hline 16 & Hungary [32] & 16.0 & 30 & 0.2 \\
\hline 17 & Sweden** & 15.9 & . & . \\
\hline 18 & Mexico [33] & 15.9 & 6 & $<0.1$ \\
\hline 319 & Korea, Rep. [34] & 14.8 & 23 & 0.2 \\
\hline 420 & Switzerland [35] & 12.4 & 108 & 0.9 \\
\hline
\end{tabular}

\section{Discussion}

This is the first study to look at the geographical accessibility of yellow fever vaccination centres in England, Wales, and Northern Ireland. For comparison, recent studies of geographical accessibility to GP practices and pharmacies found that $84.8 \%$ of the general population in England and Wales lived within $1.6 \mathrm{~km}$ of a GP practice [36]; for pharmacies it was $89.2 \%$ [37]. In the present study, only $56 \%$ of the population lived within $1.6 \mathrm{~km}$ of a yellow fever vaccination centre. For comparison, the number of active GP practices in England and Wales in August 2016 was 11,456 [38] and the number of pharmacies, 13,104 [39], whereas only 3,157 yellow fever vaccination centres were registered in England and Wales in October 2016. Only 1\% of the population lived more than $16.1 \mathrm{~km}$ away from a yellow fever vaccination centre. So, while the geographical accessibility of yellow fever vaccination centres is poorer than for general medical services, it does not seem unreasonable taking into account that long-haul trips to countries with yellow fever risk are likely to be planned and are, typically, private undertakings [40].

There was a linear relationship between the estimated number of yellow fever vaccines administered and the number of trips to countries with yellow fever risk by UK Region, which indicate that there is balance between 
supply and demand and hence an even service availability at the regional level. No under-served regions were -

1

2

3

4

5

6 7 8

in other words - identified.

The number of centres per 100,000 international trips abroad was 6.1 in England, Wales, and Northern Ireland, which was below that of United States (12.1) and above the rest of World Top20 countries in terms of trips abroad (Table 4). The reasons for the large variation internationally are likely to be different travel patterns/demand and differences in healthcare system.

The detailed data of the accessibility of yellow fever vaccination centres, will allow the regulator to make contingency plans for future vaccine shortages to ensure that vaccination services can be accessed across all regions. It will, as an example, be possible to run various scenarios to see the impact on regional accessibility if the number of active centres were to drop during a shortage.

There are a few limitations with using the International Passenger Survey (IPS) data to estimate the regional demand of yellow fever vaccinations. First, the IPS does not record all trips on cruise ships (not at all if embarkation was in the UK) and the trip may simply be recorded as 'cruising' as a generic, multi-country destination. In 2015, UK residents undertook an estimated 1.78 million cruise trips (7.7\% of global figures) [41]. More detailed UK data were not available to estimate the number of trips that would have required yellow fever vaccination either due to exposure risk or itinerary-based vaccination certificate requirements. Data on the cruise tourism industry as a whole in 2011, however, suggest that only a small fraction of cruise trips is likely to require yellow fever vaccination [42]. The Caribbean and the Mediterranean account for more than $70 \%$ of bed-days. Within the Caribbean most itineraries cover the ports in the United States, Bahamas, Eastern and Western Caribbean and the South American ports are much less visited. Most cruises only take seven days and use hub ports such as Miami, Fort Lauderdale, or San Juan, Puerto Rico, in the northern half of the Caribbean. South America accounts for $5.4 \%$ of the global number of bed-days and the majority of visits are to certain coastal regions outside the yellow fever risk areas. Future studies of actual itineraries (including inland trips and excursions) may be able to more realistically highlight any discrepancies between risk and protection, e.g. in South America and Eastern Panama [43]. Second, the data for yellow fever risk are provided by WHO at the country-level, whereas in practice it will for countries only partly endemic depend on a risk assessment of the individual traveller including regions to be visited within a country (which may change during large outbreaks), duration, and planned activities. Examples of countries that are only partly endemic are Brazil, 
Peru, and Kenya. Third, if a traveller plan to visit more than one country, the IPS record relate to the country

1

2

3

4

5

6 7

8

9 where the traveller spend the most time. A travel itinerary where a yellow fever risk country is only a secondary destination would therefore not be counted. Fourth, the IPS only cover about $0.2 \%$ of all trips abroad [1] and rarely visited destinations may not be detected.

\section{Conclusion}

The geographical accessibility of yellow fever vaccination centres was good across all major population centres considering that that long-haul trips to countries with yellow fever risk are likely to be planned. Vaccines administered was found correlated with the number of trips to yellow fever countries at regional level in England, Wales, and Northern Ireland, which indicate an even service availability. A large variation was found between countries in the number of yellow fever vaccination centres per trips abroad. England, Wales, and Northern Ireland were together with United States and the Netherlands among the countries with the most yellow fever vaccination centres per trips abroad. The reasons for the large variation internationally are likely to be different travel patterns/demand and differences in healthcare system.

\section{Acknowledgement}

The authors are indebted to anonymous health professionals in various countries, who assisted with links to websites with information about yellow fever vaccination centres open to the general public.

\section{Funding}

This research did not receive any specific grant from funding agencies in the public, commercial, or not-forprofit sectors.

\section{References}

[1] Office for National Statistics. Travel trends 2016. https://www.ons.gov.uk/peoplepopulationandcommunity/leisureandtourism/articles/traveltrends/201 5 (accessed February 21, 2017).

[2] Gostin LO, Katz R. The International Health Regulations: The Governing Framework for Global Health Security. Milbank Q 2016;94:264-313. doi:10.1111/1468-0009.12186.

[3] WHO. Yellow fever fact sheet. WHO 2016. http://www.who.int/mediacentre/factsheets/fs100/en/ (accessed February 21, 2017).

[4] Schönenberger S, Hatz C, Bühler S. Unpredictable checks of yellow fever vaccination certificates upon arrival in Tanzania. J Travel Med 2016;23. doi:10.1093/jtm/taw035.

[5] Simons H, Patel D. International Health Regulations in practice: Focus on yellow fever and poliomyelitis. Hum Vaccines Immunother 2016;12:2690-3. doi:10.1080/21645515.2016.1218100. 
[6] WHO. The yellow fever outbreak in Angola and Democratic Republic of the Congo ends 2017. http://www.afro.who.int/media-centre/pressreleases/item/9377-the-yellow-fever-outbreak-in-angolaand-democratic-republic-of-the-congo-ends.html?lang=en (accessed February 21, 2017).

[7] Wilder-Smith A, Monath TP. Responding to the threat of urban yellow fever outbreaks. Lancet Infect Dis 2016. doi:10.1016/S1473-3099(16)30588-6.

[8] Vasconcelos PFC, Monath TP. Yellow Fever Remains a Potential Threat to Public Health. Vector Borne Zoonotic Dis Larchmt N 2016;16:566-7. doi:10.1089/vbz.2016.2031.

[9] Boddington NL, Simons H, Launders N, Gawthrop M, Stillwell A, Wong C, et al. Evaluation of travel medicine practice by yellow fever vaccination centers in England, Wales, and Northern Ireland. J Travel Med 2012;19:84-91. doi:10.1111/j.1708-8305.2011.00587.x.

[10] Cromley EK, McLafferty SL. GIS and Public Health, Second Edition. Guilford Press; 2011.

[11] Office for National Statistics. ONS Postcode Directory, August 2016 (v2). 2016.

[12] Office for National Statistics. Population estimates - Office for National Statistics 2016. http://www.ons.gov.uk/peoplepopulationandcommunity/populationandmigration/populationestimates (accessed November 18, 2016).

[13] Northern Ireland Statistics and Research Agency. NISRA - Demography 2016. http://www.nisra.gov.uk/demography/default.asp17.htm (accessed November 18, 2016).

[14] Picard R. GEODIST: Stata module to compute geodetic distances. Stat Softw Compon 2012.

[15] Edinburgh University Data Library. EDINA 2016. http://edina.ac.uk/ (accessed November 18, 2016).

[16] Quantum GIS. Quantum GIS (QGIS) 2016. http://www.qgis.org/en/site/ (accessed November 18, 2016).

[17] WHO. Annex 1 - Countries with risk of yellow fever transmission and countries requiring yellow fever vaccination: 2016 updates. WHO 2016. http://www.who.int/ith/en/ (accessed January 3, 2017).

[18] Worldbank. International tourism, number of departures 2017. http://data.worldbank.org/indicator/ST.INT.DPRT (accessed April 11, 2017).

[19] StataCorp. Stata Statistical Software: Release 14. 2015.

[20] China General Administration of Quality Supervision,Inspection and Quarantine of the PRC(AQSIQ). International Travel Health Care Centers 2017. http://english.aqsiq.gov.cn/SpecialTopics/InternationalTravelHealthCare/InfoResources/200708/t2007 0816_36048.htm (accessed April 11, 2017).

[21] Centrum für Reisemedizin (CRM). Reisemedizinische Beratungsstellen 2017. http://www.crm.de/beratungsstellen/index.asp (accessed April 11, 2017).

[22] Hongkong Department of Health. Travel Health Service Yellow Fever 2017. http://www.travelhealth.gov.hk/english/faqs/yell_fever.html (accessed April 11, 2017).

[23] CDC. Search for Yellow Fever Vaccination Clinics, Travelers' Health 2017. https://wwwnc.cdc.gov/travel/yellow-fever-vaccination-clinics/search (accessed March 21, 2017).

[24] Mir Travel. Вакцинация против желтой лихорадки [Yellow fever vaccination] 2017. http://www.mirtravel.com/spravochnik/vaktsinatsija_protiv_zheltoj_lixoradki (accessed April 11, 2017).

[25] Public Health Agency of Canada. Yellow Fever Vaccination Centres in Canada - Travel Health 2017. http://www.phac-aspc.gc.ca/tmp-pmv/yf-fj/index-eng.php (accessed March 21, 2017).

[26] Salute M della. Vaccinazione Febbre gialla [Yellow fever vaccination] 2017. http://www.salute.gov.it/portale/temi/p2_6.jsp?id=765\&area=Malattie\%20infettive\&menu=viaggiatori (accessed April 11, 2017).

[27] Ministère des Affaires sociales et de la Santé. Liste des centres de vaccination habilités à effectuer la vaccination contre la fièvre jaune (anti-amarile). Ministère Aff Soc Santé 2017. http://socialsante.gouv.fr/prevention-en-sante/preserver-sa-sante/vaccination-fievre-jaune (accessed March 21, 2017).

[28] Daleeli.com. Hospitals in Saudi Arabia - KSA - Online Business Directory 2017. http://www.daleeli.com/en/category/all/all/Hospitals/12300 (accessed April 11, 2017).

[29] Landelijk Coördinatiecentrum Reizigersadvisering. Vaccinatie-adressen 2017. https://www.lcr.nl/Vaccinatie-adressen (accessed April 11, 2017).

[30] FORTH. 黄熱の予防接種を行っている検疫所 [Yellow fever vaccination quarantine station] 2017. http://www.forth.go.jp/useful/yellowfever.html\#list (accessed April 11, 2017).

[31] Ministry of Health \& Family Welfare. Yellow Fever 2017. http://www.mohfw.nic.in/index1.php?lang=1\&level=1\&sublinkid=1342\&lid=1259 (accessed April 11, 2017).

[32] Personal communication. Yellow fever vaccination centres in Hungary, Dr. Peter Felkai, March 20172017. 
[33] Secretaria de Salud. Vacunación para viajeros internacionales. Gob.mx 2017.

http://www.gob.mx/salud/acciones-y-programas/vacunacion-para-viajeros-internacionales (accessed April 11, 2017).

[34] Republic of Korea Ministry of Health. Infectious disease management - Rio Olympics 2017. http://www.mohw.go.kr/front_new/al/sal0301vw.jsp?PAR_MENU_ID=04\&MENU_ID=0403\&page=1\&CO NT_SEQ=333281\&SEARCHKEY=TITLE\&SEARCHVALUE=\%B8\%AE\%BF\%EC (accessed April 11, 2017).

[35] Safetravel.ch. Lieux de vaccination 2017. http://www.safetravel.ch/safetravel2/servlet/ch.ofac.wv.wv205j.pages.Wv205LieuxVaccinationCtrl?acti on=recherche (accessed April 11, 2017).

[36] Todd A, Copeland A, Husband A, Kasim A, Bambra C. Access all areas? An area-level analysis of accessibility to general practice and community pharmacy services in England by urbanity and social deprivation. BMJ Open 2015;5:e007328. doi:10.1136/bmjopen-2014-007328.

[37] Todd A, Copeland A, Husband A, Kasim A, Bambra C. The positive pharmacy care law: an area-level analysis of the relationship between community pharmacy distribution, urbanity and social deprivation in England. BMJ Open 2014;4:e005764. doi:10.1136/bmjopen-2014-005764.

[38] NHS. GPs, GP Practices, Nurses and Pharmacies - NHS Digital 2016. http://systems.digital.nhs.uk/data/ods/datadownloads/gppractice/index_html (accessed November 18, 2016).

[39] General Pharmaceutical Council. General Pharmaceutical Council, Registers 2017. https://www.pharmacyregulation.org/registers (accessed February 21, 2017).

[40] Steele S, Freitag A, McGettigan P, Giovannoni G, Pollock AM. A guide to private prescribing. Prescriber 2015;26:19-23. doi:10.1002/psb.1324.

[41] Business Research \& Economic Advisors. The Global Economic Contribution of Cruise Tourism 2015. Exton, Pennsylvania: 2016.

[42] Rodrigue J-P, Notteboom T. The geography of cruises: Itineraries, not destinations. Appl Geogr 2013;38:31-42. doi:10.1016/j.apgeog.2012.11.011.

[43] De Cantis S, Ferrante M, Kahani A, Shoval N. Cruise passengers' behavior at the destination: Investigation using GPS technology. Tour Manag 2016;52:133-50. doi:10.1016/j.tourman.2015.06.018.

\section{FIGURE LEGENDS}

Figure 1 Distance to nearest yellow fever vaccination centre for the general population by UK Region (km).

Figure 2 Distance $(\mathrm{km})$ to nearest yellow fever vaccination centre in England, Wales, and Northern Ireland (lower layer super output area level).

Figure 3 Estimated number of yellow fever vaccinations and trips to countries with yellow fever risk by region of residence in England, Wales, and Northern Ireland. Labels: North East (NE), North West (NW), Yorkshire \& The Humber (YH), East Midlands (EM), West Midlands (WM), East of England (EE), London (LO), South East (SE), South West (SW), Wales (WA), Northern Ireland (NI). 


\section{Distance to Nearest Centre by Region}

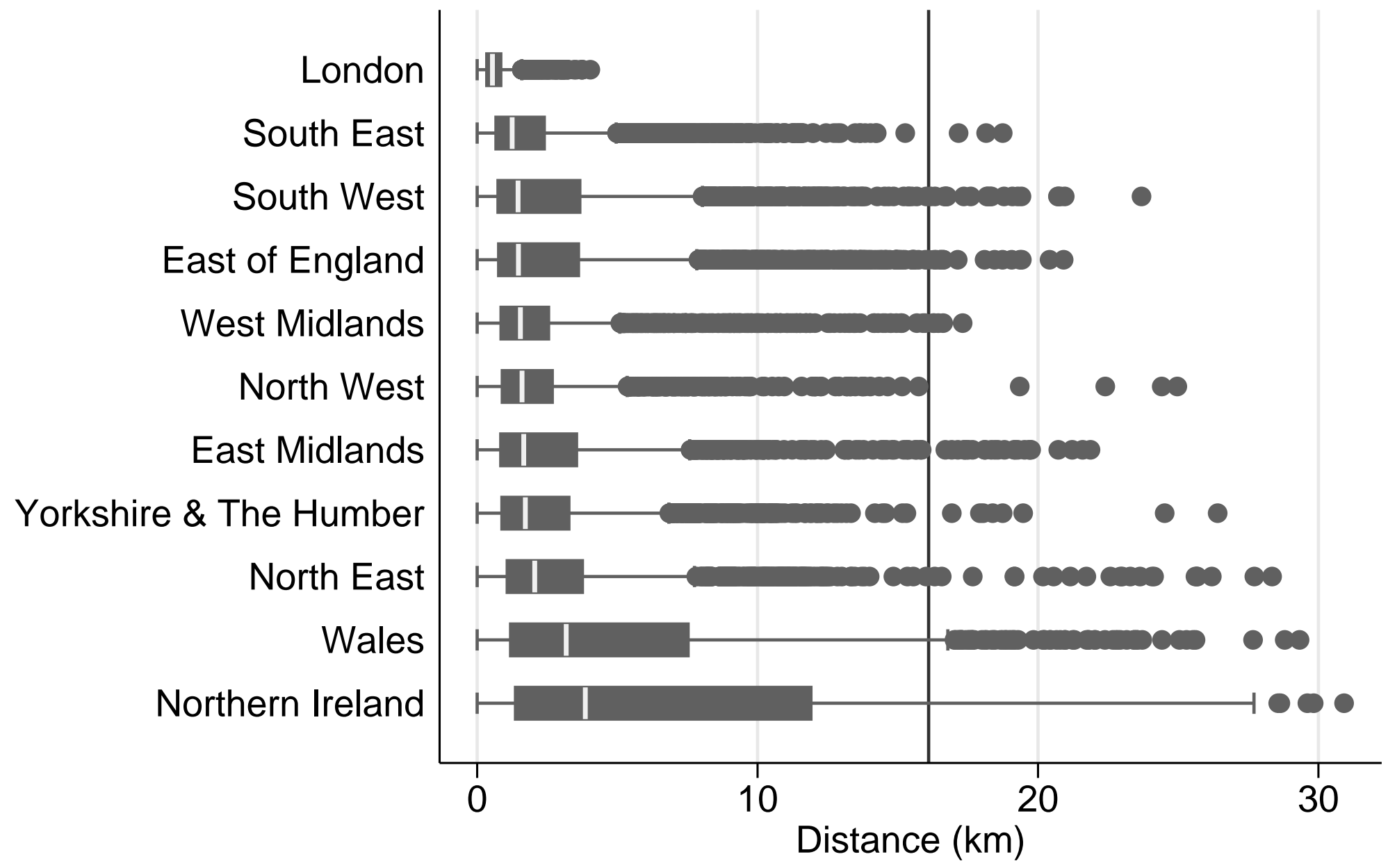

Yellow Fever Vaccination Programme 2016

Vertical line: $16.1 \mathrm{~km}$ (p99) 
Figure
Click here to download high resolution image

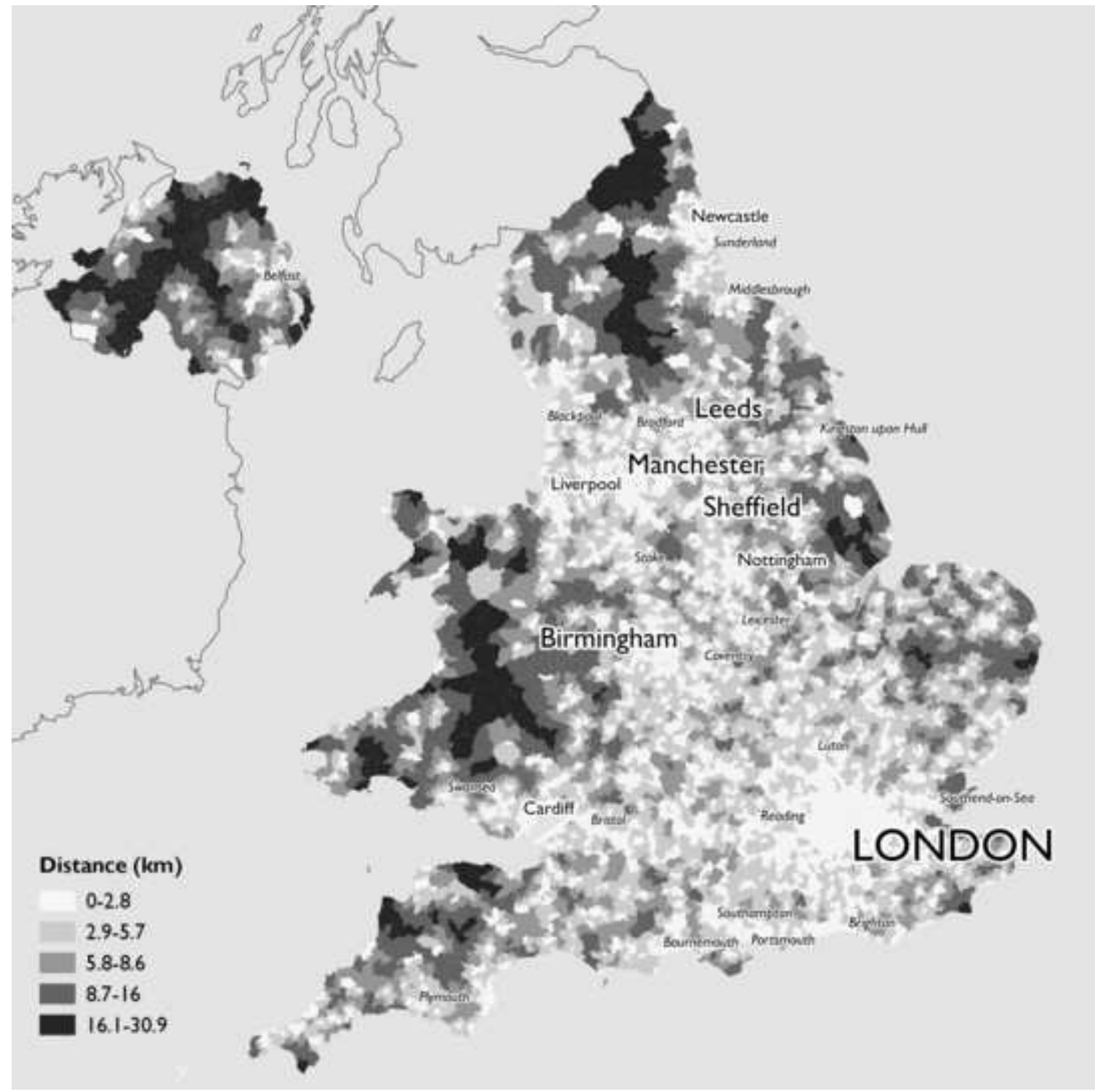




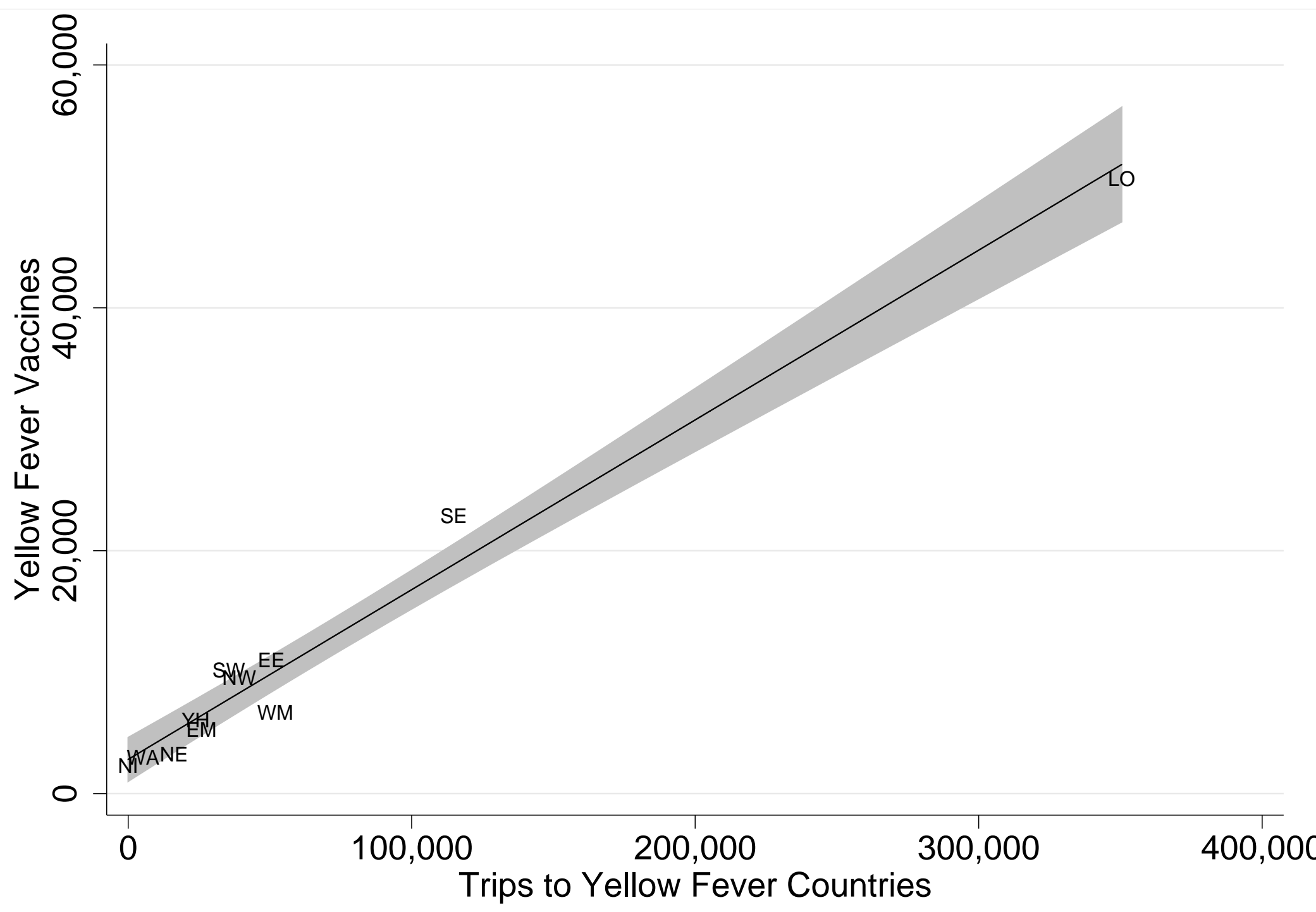

Vaccines $=0.14$ * Trips $+2817 ;$ R-squared: 0.98 . 